Check for updates

Cite this: Mater. Adv., 2021, 2, 303

Received 15th June 2020, Accepted 20th October 2020

DOI: 10.1039/d0ma00417k

rsc.li/materials-advances

\section{Phase formation of manganese oxide thin films using pulsed laser deposition $\uparrow$}

\author{
Lauren M. Garten, (D)* Praneetha Selvarasu, (D) § John Perkins, $\uparrow$ David Ginley and \\ Andriy Zakutayev (D) *
}

\begin{abstract}
Manganese oxides have enabled a wide range of technologies including oxygen evolution catalysts, lithium ion batteries, and thermochemical water splitting. However, the variable oxidation state and rich polymorphism of manganese oxides make it difficult to find the processing conditions to target a particular phase of manganese oxide. Targeted synthesis requires a more complete understanding of the phase space and the impact of multiple processing variables on phase formation. Here, we demonstrate the impact of substrate temperature, total deposition pressure, partial pressure of oxygen, and target composition on the phase formation of manganese oxides grown using combinatorial pulsed laser deposition (PLD). Thin films were deposited from a $\mathrm{MnO}, \mathrm{Mn}_{2} \mathrm{O}_{3}$ or $\mathrm{MnO}_{2}$ target onto amorphous glass substrates with a continuously varied temperature provided by a combinatorial heater. A combination of $X$-ray diffraction, Rutherford backscattering spectroscopy, and Raman and Fourier transform infrared (FTIR) spectroscopies were used to determine the phases present in the samples. The oxygen partial pressure was found to be the critical factor determining phase formation, while the total pressure, target composition, and substrate temperature have smaller and more complex effects on phase formation. Comparing the results of this work to the published temperature-pressure phase diagrams shows that the PLD thin films vary significantly from the expected equilibrium phases of either the bulk materials or nanoparticles. These results suggest that PLD provides a route to capture phases of manganese oxides at lower temperatures or higher oxygen pressures than those required for bulk synthesis or solution processing.
\end{abstract}

\section{Introduction}

Manganese oxides have enabled the development of lithium ion batteries, ${ }^{1,2}$ aqueous flow batteries, ${ }^{3}$ oxygen evolution electrocatalysts, ${ }^{4}$ thermochemical water splitting, ${ }^{5}$ and other energyrelated technologies. The same features that make manganese oxides critical for these applications - a variable oxidation state and rich polymorphism ${ }^{6,7}$ - also make it difficult to predict the phase that will form for a given set of processing conditions. Recent advances in density functional theory (DFT) have enabled the calculation of the thermodynamic ground state structures, and even some non-equilibrium crystallization pathways for a few manganese oxides over a range of proton $(\mathrm{pH})$

National Renewable Energy Laboratory, Golden, CO, 80401, USA.

E-mail:Img356@gmail.com, andriy.zakutayev@nrel.gov

$\dagger$ Electronic supplementary information (ESI) available. See DOI: 10.1039/d0ma00417k ‡ Present address: U.S. Naval Research Laboratory, 4555 Overlook Ave SW, Washington, D.C. 20375, USA.

$\S$ Present address: Indian Institute of Science Education and Research, Tirupati, India.

T Present address: National Institute of Standards and Technology, 325 Broadway, Boulder, CO 80305, USA. and alkali concentrations. ${ }^{6,8}$ In turn, this ab initio framework has allowed the prediction of how particle size and solution composition would influence the polymorph stability in $\mathrm{MnO}_{2}$ grown from an alkali containing solution. ${ }^{9}$ But, it is not yet clear how these results will translate to other synthetic techniques, specifically vacuum based methods, where the absence of hydration or alkali could drive the phase formation through other pathways.

Pulsed Laser Deposition (PLD) is a vacuum based deposition method that has the benefits of creating high quality films that typically retain the target composition. PLD is also known to be a non-equilibrium growth method. ${ }^{10,11}$ For manganese oxides processed using PLD, there is the added benefit of avoiding any binders or alkali, which clearly play a role in other processing methods. Thus, PLD growth provides phase information that is more independent of the synthetic environment and could capture a broader range of phases. Since the size scales and hydration levels of PLDsynthesized materials can be very different from those of either bulk synthesis or solution processing, it is worth developing an understanding of what manganese oxide phases can be attained as a function of PLD processing conditions.

There have been a few studies on the PLD growth of manganese oxides, each covering a narrow portion of the phase space. 
Thin films grown from a $\mathrm{MnO}$ target at a partial pressure of oxygen below 0.01-0.1 torr formed the $\mathrm{Mn}_{2} \mathrm{O}_{3}$ phase at temperatures from 550 to $700{ }^{\circ} \mathrm{C}$ and the $\mathrm{Mn}_{3} \mathrm{O}_{4}$ phase from 700 to $850{ }^{\circ} \mathrm{C} .{ }^{12}$ These results are qualitatively similar but quantitatively different from those of the bulk phase diagram. The films deposited from a Mn target at $600{ }^{\circ} \mathrm{C}$ in an oxygen environment formed the $\mathrm{Mn}_{2} \mathrm{O}_{3}$ phase at 0.7 torr, $\mathrm{Mn}_{3} \mathrm{O}_{4}$ at 0.1 torr and the $\mathrm{MnO}$ phase under vacuum $\left(10^{-5}\right.$ torr); the $\mathrm{Mn}_{3} \mathrm{O}_{4}$ was used as an anode for microbatteries. ${ }^{13}$ Films deposited from a $\mathrm{MnO}_{2}$ target at 0.1 torr of oxygen showed various $\mathrm{MnO}_{2}$ phases at temperatures from 300 to $450{ }^{\circ} \mathrm{C}$ (which were used for Na-ion batteries) and also some $\mathrm{Mn}_{2} \mathrm{O}_{3}$ at temperatures from 550 to $650{ }^{\circ} \mathrm{C}^{14}$ Several combinations of temperatures $\left(200-700{ }^{\circ} \mathrm{C}\right)$ and pressures $\left(3 \times 10^{-7}-0.5\right.$ torr $)$ were also used to ablate $\mathrm{Mn}$ and $\mathrm{Mn}_{3} \mathrm{O}_{4}$ targets, resulting in the formation of $\mathrm{Mn}_{2} \mathrm{O}_{3}$ and/or $\mathrm{Mn}_{3} \mathrm{O}_{4}$ phases, which were used for supercapacitor applications. ${ }^{15}$ Sputtering (another form of physical vapour deposition) has also been used to grow manganese oxide thin films, where the temperature, partial pressure of oxygen, and thin film morphology have been found to be critical in determining the oxidation state and preformance., 2,16,17

High-throughput experimental (HTE) combinatorial research methods are well suited to mapping the complex processingcomposition-structure relationships of materials in thin film form. ${ }^{18,19}$ In particular, combinatorial PLD can rapidly identify the key variables directing phase formation in ternary and more complex materials using metal composition arrays. ${ }^{20,21}$ However, combinatorial PLD studies are more rare for simple binary compounds with no gradients in composition of metallic elements. $^{22,23}$ It has been shown that a substrate temperature gradient can be used for the combinatorial PLD screening of the binary oxide processing window and for targeting a specific metal oxide phase. ${ }^{24,25}$

In this work, the influences of substrate temperature, target composition, total deposition pressure, and the partial pressure of oxygen on manganese oxide phase formation are investigated using combinatorial PLD deposition from $\mathrm{MnO}, \mathrm{Mn}_{2} \mathrm{O}_{3}$ and $\mathrm{MnO}_{2}$ targets. The phase formation is determined using X-ray diffraction (XRD), and Raman and Fourier transform infrared (FTIR) spectroscopies: a combination of all methods is needed to identify the phases that formed. The oxygen partial pressure during deposition is the critical factor that determines which phase would form, while the total chamber pressure, substrate temperature, and target composition have a smaller and more complicated effect on phase formation. The results from each of these experiments are compiled into an effective phase diagrams for PLD processing of manganese oxides and compared to the equilibrium phase diagram for bulk synthesis and nanoparticle processing. It is shown that PLD is able to achieve manganese oxide phases at reduced temperatures or higher oxygen pressures compared to the bulk- or nanoparticle phase diagram, which may be beneficial for practical applications.

\section{Methods}

Thin film libraries were deposited using combinatorial pulsed laser deposition (PLD) onto Eagle XG glass substrates (Corning Inc.) from
$\mathrm{MnO}, \mathrm{Mn}_{2} \mathrm{O}_{3}$ and $\mathrm{MnO}_{2}$ targets (Materion, 99.995\%). Prior to deposition, the substrates were ultrasonicated in deionized (DI) water, acetone, and isopropyl alcohol for five minutes each and then cleaned by oxygen plasma ashing for 5 minutes. The PLD instrument employed a $248 \mathrm{~nm} \mathrm{KrF}$ laser (Coherent). The libraries were deposited at an energy density of approximately $2.2 \mathrm{~J} \mathrm{~cm}^{-2}$ at the target; the laser pulse frequency was $10 \mathrm{~Hz}$ and the target substrate distance was $6 \mathrm{~cm}$. The base pressure of the chamber was $10^{-8}$ torr or lower at ambient temperature and $10^{-6}$ torr at the processing temperatures (this higher value was used for plotting). The total pressure and partial pressure of oxygen were held constant for the deposition of each library but were varied between libraries from $10^{-1}$ to $10^{-5}$ torr. Argon (Ar) was used to balance the difference between the partial pressure of oxygen $\left(p_{\mathrm{O}_{2}}\right)$ and the total desired chamber pressure ( $\left.p_{\text {tot }}\right)$. A constant temperature difference was applied to the substrate during growth by mounting the glass substrate along one edge such that the rest of the substrate was freely suspended. The reason for using this fixture was that the temperature could be varied continuously over the same library from approximately $550{ }^{\circ} \mathrm{C}$ to $250{ }^{\circ} \mathrm{C}$. The fixture used to apply a temperature difference across a library has been described previously. ${ }^{24}$

The crystal structure of the films was characterized using a Bruker Discover D8 X-ray diffractometer with a $\mathrm{Cu} \mathrm{K} \alpha$ source and a two-dimensional detector. Raman spectroscopic studies were carried out using a Renishaw InVia instrument with an excitation wavelength of $532 \mathrm{~nm}$. Fourier transform infrared (FTIR) spectroscopy was performed using a Thermo-Nicolet Nexus 870 FTIR Spectrometer with an Image Max Microscope. The average Mn:O ratio was measured using Rutherford backscattering spectroscopy (RBS) with a $2 \mathrm{MeV} \mathrm{He}^{+}$beam in a $110^{\circ}$ scattering angle geometry. The scattering angle was chosen to optimize the separation of $\mathrm{Mn}$ and $O$ in the film with the substrate $O$ signal. The data analysis for these samples was conducted using CombIgor, a data analysis package for combinatorial experimentation. ${ }^{26}$ These data and a range of combinatorial data for many other materials can be assessed at the High Throughput Experimental Materials Database (HTEM DB). ${ }^{27}$

\section{Results}

Manganese oxide combinatorial libraries were deposited over a range of substrate temperature, total pressure, partial pressure of oxygen, and target composition to track the impact of these variables on the thin film phase formation. Table S1 (ESI $\dagger$ ) provides further information on the target composition, partial pressure of oxygen $\left(p_{\mathrm{O}_{2}}\right)$, and total pressure $\left(p_{\text {tot }}\right)$ for each of the libraries in this study. The major results of Raman spectroscopy and X-ray diffraction are summarized for each library and the figure in which this information is shown is given in the last column of the table. Results from previous work using a $\mathrm{MnO}$ target are included as well for comparison. ${ }^{28}$ Below, we present phase identification using XRD patterns and Raman spectra for sample libraries deposited from the $\mathrm{Mn}_{2} \mathrm{O}_{3}$ target at two different oxygen partial pressures (Fig. 1 and 2), and then summarize the 


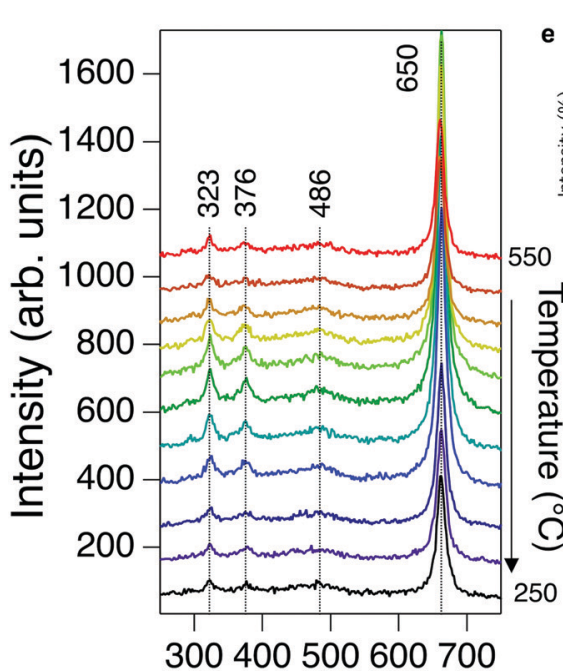

a.
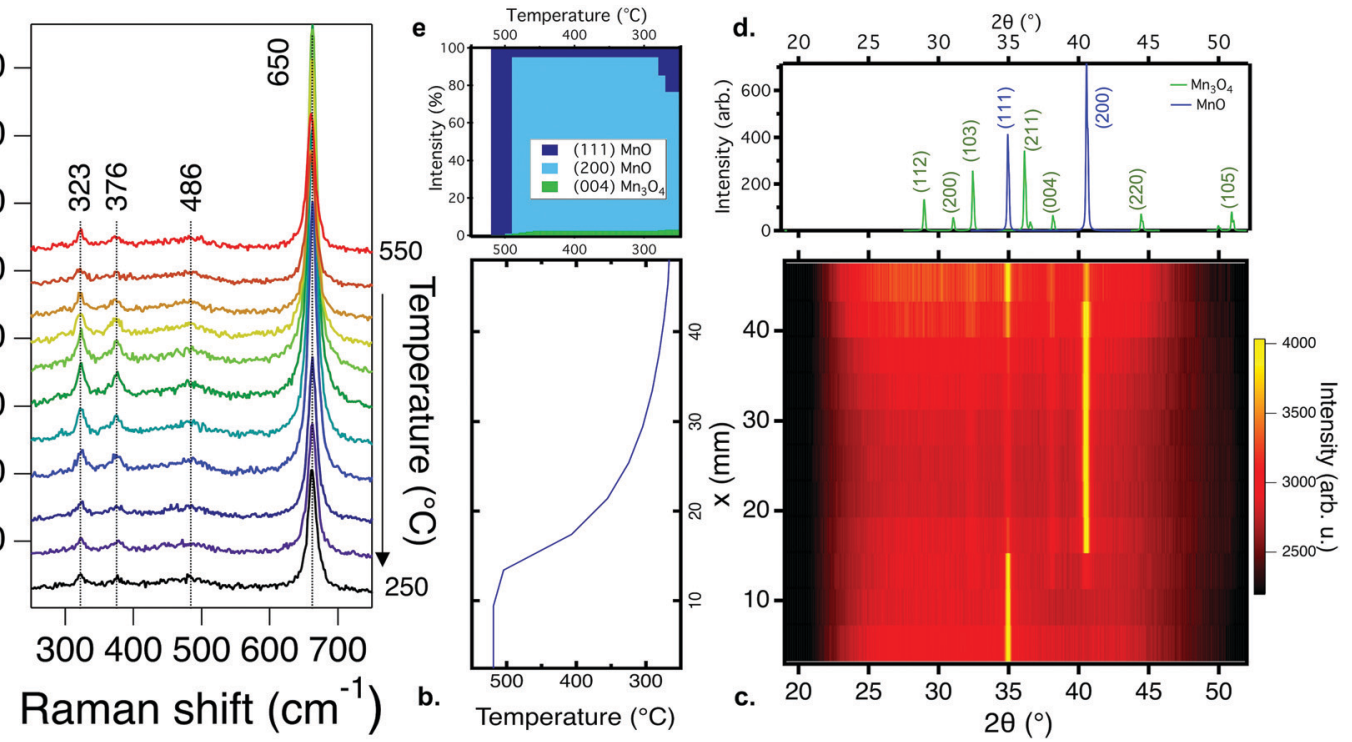

Fig. 1 Phase identification for a manganese oxide combinatorial library deposited from a $\mathrm{Mn}_{2} \mathrm{O}_{3}$ target at a partial pressure of oxygen of $10^{-3}$ torr and a total chamber pressure of $10^{-2}$ torr, at substrate temperatures from $550{ }^{\circ} \mathrm{C}$ to $250{ }^{\circ} \mathrm{C}$ : (a) Raman spectroscopy results. All scans show peaks consistent with the $\mathrm{Mn}_{3} \mathrm{O}_{4}$ phase, but complementary FTIR (Fig. S2, ESI $\dagger$ ) results indicate the presence of $\mathrm{MnO}$; (b) the substrate temperature profile as a function of position in the library, used for the XRD color intensity plot; (c) the X-ray diffraction, with diffraction intensity shown by the color scale. A combination of $\mathrm{MnO}$ and $\mathrm{Mn}_{3} \mathrm{O}_{4}$ phases is present; (d) the reference XRD diffraction patterns for $\mathrm{MnO}$ and $\mathrm{Mn}_{3} \mathrm{O}_{4}$; (e) the change in normalized diffraction intensity for the three highest intensity peaks: (111) $\mathrm{MnO},(200) \mathrm{MnO}$, and (103) $\mathrm{Mn}_{3} \mathrm{O}_{4}$, as a function of temperature.

phases identified in the films deposited from all targets and all total pressures (Fig. 3). The XRD patterns and Raman spectra for all the other targets and conditions, as well as supporting RBS and FTIR data for selected samples, are provided in the ESI. $\dagger$

Fig. 1a shows the Raman spectra for a combinatorial library deposited from a $\mathrm{Mn}_{2} \mathrm{O}_{3}$ target, spanning a temperature range of approximately $550{ }^{\circ} \mathrm{C}$ to $250{ }^{\circ} \mathrm{C}$, at a constant partial pressure of oxygen of $10^{-3}$ torr and a total chamber pressure of $10^{-2}$ torr. The peaks at 323, 376, 486 and $650 \mathrm{~cm}^{-1}$ are consistent with the Raman spectra for $\mathrm{Mn}_{3} \mathrm{O}_{4} \cdot{ }^{31}$ No significant change in the position of the Raman peaks is observed for films grown over this temperature range. The changes in intensity stem from the difference in thickness from the center to edges of the library. A similar Raman response was observed for all samples processed at or below $10^{-3}$ torr of oxygen, down to the base pressure, and for samples deposited under similar conditions from a $\mathrm{MnO}_{2}$ target. Over this pressure range, $\mathrm{Mn}_{3} \mathrm{O}_{4}$ formed regardless of the total pressure or the target used for deposition. Further details on these results for both $\mathrm{Mn}_{2} \mathrm{O}_{3}$ and $\mathrm{MnO}_{2}$ targets as a function of pressure are shown in the ESI. $\dagger$

While the Raman spectra show only the MnO phase, Fourier transform infrared (FTIR) spectroscopy and Rutherford backscattering spectroscopy (RBS) results suggest that the combinatorial library contains $\mathrm{MnO}$ and $\mathrm{Mn}_{3} \mathrm{O}_{4}$ phases across the entire temperature range, as presented and discussed in the ESI $\dagger$ (Fig. S2 and S3). To reconcile these observations, X-ray diffraction measurements were performed to obtain a more complete picture of the phase formation. Fig. $1 \mathrm{~b}$ and $\mathrm{c}$ show the temperature gradient and the X-ray diffraction data obtained for the same library as that characterized in Fig. 1a. Multiple phases can be clearly observed to coexist and change with temperature. At the highest temperatures, $550-500{ }^{\circ} \mathrm{C}$, the XRD pattern fits best with $\mathrm{MnO}(F m \overline{3} m),{ }^{32}$ transitioning to a mixture of $\mathrm{MnO}$ and $\mathrm{Mn}_{3} \mathrm{O}_{4}$ $\left(I 4_{1} / \text { amd }\right)^{33}$ below $500{ }^{\circ} \mathrm{C}$. The total XRD intensity of the $\mathrm{Mn}_{3} \mathrm{O}_{4}$ phase is low and the peak width is large, indicating either small phase regions and/or small crystallite sizes. The phase identification results for the sample libraries deposited from other targets and at other total pressures are qualitatively similar, with some differences in film crystallinity (Fig. S4, ESI $\dagger$ ), and are presented in the ESI. $\dagger$

Increasing the partial pressure of oxygen during growth beyond $10^{-3}$ torr leads to the formation of different phases. Fig. 2a-e show the Raman and XRD results for films processed under these conditions. Fig. $2 \mathrm{~b}$ shows the temperature gradient across the samples, and Fig. $2 \mathrm{c}$ shows the XRD pattern of a thin film library deposited from a $\mathrm{Mn}_{2} \mathrm{O}_{3}$ target with an oxygen partial pressure of $10^{-2}$ torr and a total pressure of $10^{-2}$ torr. The films are (222)-oriented $\mathrm{Mn}_{2} \mathrm{O}_{3}$ (the PDF standard is shown in Fig. 2d). Fig. 2e shows the phase percentage obtained from XRD compared to that of the Raman results. According to XRD, only $\mathrm{Mn}_{2} \mathrm{O}_{3}$ is present; no other secondary phases are observed. The ground state of $\mathrm{Mn}_{2} \mathrm{O}_{3}$ at room temperature has an orthorhombic distorted bixbyite structure, but the XRD data here fit to cubic $\mathrm{Mn}_{2} \mathrm{O}_{3}$ (Ia3, ICDD 00-041-1442) $)^{34}$ for all temperatures. A similar XRD pattern is observed for all films grown at a $p_{\mathrm{O} 2}$ of $10^{-2}$ torr. This observation is consistent with previous reports showing the formation of cubic $\mathrm{Mn}_{2} \mathrm{O}_{3}$ by PLD for temperatures lower than $600{ }^{\circ} \mathrm{C}^{12}$ When the pressure is increased to $10^{-1}$ torr, the films become amorphous at the highest and lowest temperatures in the library. This is different to the results of previous studies where $\mathrm{MnO}_{2}$ has been observed for films grown at and above $500{ }^{\circ} \mathrm{C}$ at $10^{-1}$ torr of oxygen, ${ }^{14}$ 


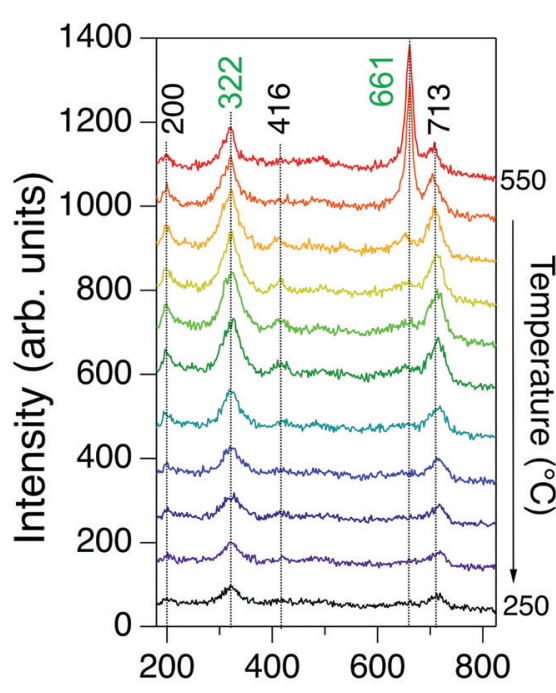

a. $\quad$ Raman shift $\left(\mathrm{cm}^{-1}\right)$

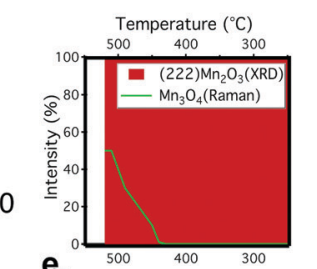

e.

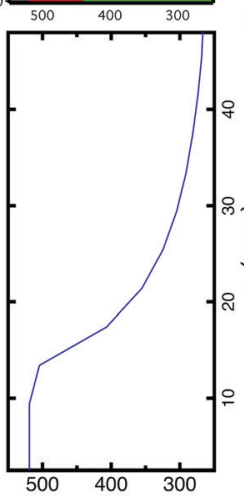

b. Temperature $\left({ }^{\circ} \mathrm{C}\right)$

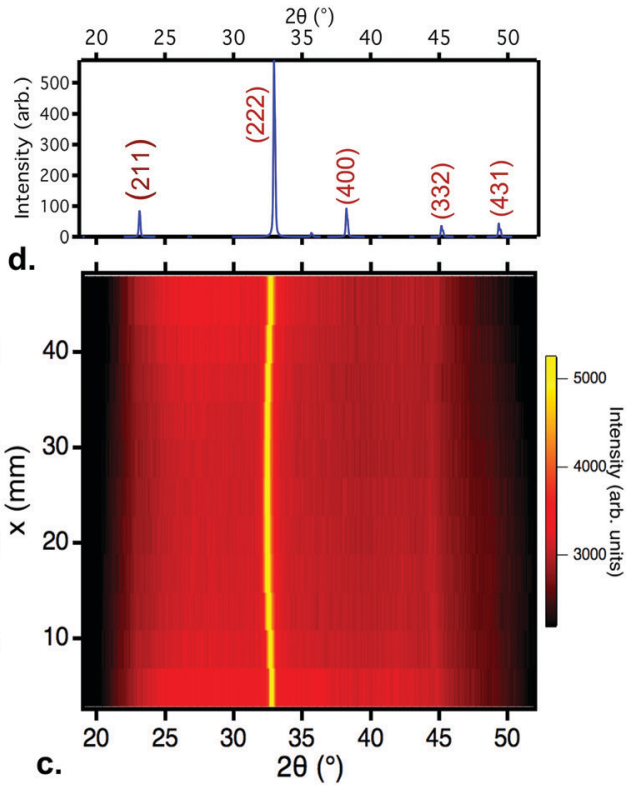

c.

Fig. 2 Phase identification for a manganese oxide combinatorial library deposited from a $\mathrm{Mn}_{2} \mathrm{O}_{3}$ target with an oxygen partial pressure of $10^{-2}$ torr and a total pressure of $10^{-2}$ torr at a substrate temperature in the range of $550{ }^{\circ} \mathrm{C}$ to $250{ }^{\circ} \mathrm{C}$ : (a) Raman spectroscopy for the same manganese oxide combinatorial library, with peaks color coded by phase (black for $\mathrm{Mn}_{2} \mathrm{O}_{3}$ and green for $\mathrm{Mn}_{3} \mathrm{O}_{4}$ ); (b) the temperature gradient as a function of position in the library; (c) the XRD map of diffraction intensity as a function of position; (d) the reference XRD diffraction pattern for $\mathrm{Mn}_{2} \mathrm{O}_{3}$; (e) the normalized diffraction intensity for the highest intensity peak (222) of $\mathrm{Mn}_{2} \mathrm{O}_{3}$, overlaid with an estimate of the phase fraction from Raman spectroscopy.

likely because higher pressures lead to greater plume scattering and a lower growth rate in PLD.

Fig. 2a shows the Raman spectra for the same sample library whose XRD patterns are shown in Fig. 2c. In agreement with the $\mathrm{XRD}$ data, the Raman response for films deposited under these conditions is consistent with modes previously observed for $\mathrm{Mn}_{2} \mathrm{O}_{3},{ }^{35}$ specifically the peaks at 200,416 and $713 \mathrm{~cm}^{-1}$. The peaks are shifted to higher wavenumbers, which has previously been observed in $\mathrm{Mn}_{2} \mathrm{O}_{3}$ under pressure, ${ }^{36}$ suggesting that the higher partial pressure during deposition strained the films. However, the appearance of a peak at $661 \mathrm{~cm}^{-1}$, along with an increase in the intensity of the peak at $322 \mathrm{~cm}^{-1}$, for the highest temperature is consistent with the formation of $\mathrm{Mn}_{3} \mathrm{O}_{4}$, which was not observed in the XRD patterns, indicating that this secondary phase is likely at a phase fraction or size scale below the detection limit of XRD. Films deposited from $\mathrm{MnO}_{2}$ targets under similar conditions show similar Raman spectroscopy trends, as shown in Fig. S5 (ESI $\dagger$ ).

Fig. 3a summarizes the dominant manganese oxide phase(s) as a function of total pressure and partial pressure of oxygen at approximately $450-500{ }^{\circ} \mathrm{C}$ for thin film libraries deposited from the $\mathrm{Mn}_{2} \mathrm{O}_{3}$ target (similar results were obtained from a $\mathrm{MnO}_{2}$ target). Increasing the total and partial pressure of oxygen above $10^{-2}$ torr leads to the formation of $\mathrm{Mn}_{2} \mathrm{O}_{3}$, as shown in Fig. 2. Decreasing the partial pressure of oxygen below $10^{-3}$ torr for total pressures below $10^{-1}$ torr leads to a mixture of $\mathrm{Mn}_{3} \mathrm{O}_{4}$ and $\mathrm{MnO}$ (shown with overlapping symbols), as shown in Fig. 1. Decreasing the partial pressure of oxygen further down to the base pressure leads to MnO becoming the predominant phase. From these data, it is clear that the critical factor in the phase formation of manganese oxide thin films is the partial pressure of oxygen during deposition, and to a lesser extent total pressure.

Fig. 3b summarizes the dominant phase(s) of manganese oxide thin film libraries deposited at approximately $450-500{ }^{\circ} \mathrm{C}$ as a function of partial pressure of oxygen and the composition of the target material. Three different values of total pressure, $p_{\text {tot }}$, were assessed, $10^{-1}$ torr, $10^{-3}$ torr, and $10^{-6}$ torr (the base pressure, $p_{\mathrm{b}}$ ). Further details on the phase formation in films deposited from a $\mathrm{MnO}_{2}$ target can be found in the ESI. $\dagger$ In agreement with the $p_{\mathrm{O}_{2}}$ vs. $p_{\text {tot }}$ phase diagram, $p_{\mathrm{O}_{2}}$ is still the dominant factor that determines the phase formation. The target composition also influences the resulting ratio of phases in the mixed-phase $\mathrm{Mn}_{3} \mathrm{O}_{4}+\mathrm{MnO}$ films grown at the same $p_{\mathrm{O}_{2}}$, with the lower oxidation state $\mathrm{MnO}$ target leading to a higher fraction of $\mathrm{MnO}$ phase compared with the higher oxidation state $\mathrm{Mn}_{2} \mathrm{O}_{3}$ and $\mathrm{MnO}_{2}$ targets.

Fig. 3c summarizes the dominant phase(s) of manganese oxide thin film libraries as a function of partial pressure of oxygen and substrate temperature, for films grown from a $\mathrm{Mn}_{2} \mathrm{O}_{3}$ target at two levels of fixed $p_{\text {tot }}$. The total pressures used for each library are shown in Fig. S6 (ESI $\dagger$ ). As discussed above, $p_{\mathrm{O}_{2}}$ is a more important factor in determining the resulting phase than the substrate temperature. This is counter to previous results on sputtered manganese oxide thin films, which reported that temperature was the most critical factor determining the oxidation state. ${ }^{16}$ However, in these PLD films, substrate temperature and $p_{\text {tot }}$ also matter, with a higher substrate temperature leading to more crystalline and more reduced films (e.g. polycrystalline $\mathrm{Mn}_{2} \mathrm{O}_{3}$ instead of nanocrystalline $\mathrm{MnO}_{2}$ ), and with films deposited at $p_{\mathrm{O}_{2}}=10^{-3}$ torr showing a more oxidized $\mathrm{Mn}_{2} \mathrm{O}_{3}$ phase at the 

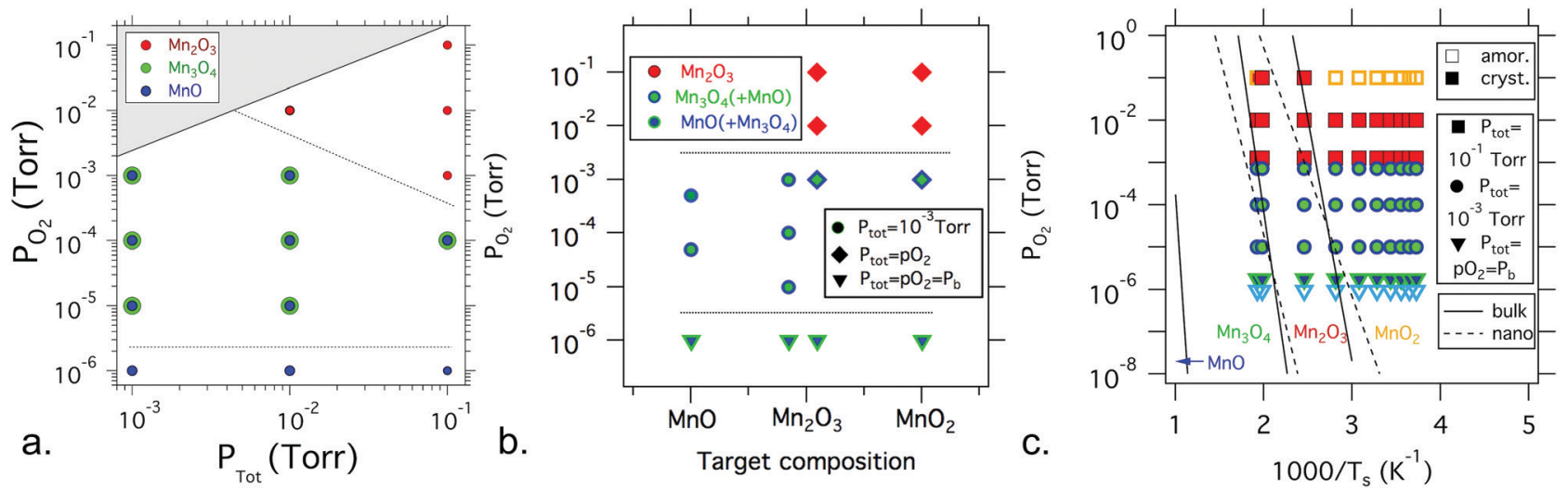

Fig. 3 Summary of phase identification for various manganese oxide sample libraries as a function of oxygen and total pressure, target choice, and substrate temperature: (a) manganese oxide phase formation as a function of partial pressure of oxygen and total pressure for films grown from a $\mathrm{Mn}_{2} \mathrm{O}_{3}$ target at a substrate temperature in the range of $400-500{ }^{\circ} \mathrm{C}$; (b) manganese oxide phase formation as a function of partial pressure of oxygen and target composition for films grown at a temperature in the range of $400-500{ }^{\circ} \mathrm{C}$ at three different total pressures; (c) phase formation as a function of partial pressure of oxygen and substrate temperature, in comparison with the bulk and nanoparticle phase diagram from ref. 29 and 30 . The symbol colors are consistent with the label colors in the phase diagram, with the mixtures of $\mathrm{Mn}_{3} \mathrm{O}_{4}$ and $\mathrm{MnO}$ shown in overlapping green and blue symbols. Light blue represents nanocrystalline $\mathrm{MnO}$. Overall, these results indicate that oxygen pressure is the dominant factor in manganese oxide thin film phase formation by PLD.

higher $p_{\text {tot }}=10^{-1}$ torr and more reduced $\mathrm{Mn}_{3} \mathrm{O}_{4}+$ MnO phase at the lower $p_{\text {tot }}=p_{\mathrm{O}_{2}}=10^{-3}$ torr.

\section{Discussion}

Comparing the phase formation observed for each thin film library with the bulk and nanoparticle phase diagrams reveals that the phases in the films are qualitatively similar but quantitatively different from what is expected in the bulk or at the nanoscale. Fig. 3c shows an overlay of the thin film results from this study compared to the bulk phase diagram ${ }^{29}$ and to that of anhydrous $10 \mathrm{~nm}$ nanoparticles of manganese oxides. ${ }^{30}$ Overall, the thin film results seem to be similar to the two phase diagrams, i.e., a lower oxygen partial pressure and higher temperature lead to more reduced phases, but with some significant differences. The phase formation regions for the thin films are pushed to lower temperatures or higher oxygen pressures compared to the published phase diagrams. MnO is grown entirely outside of the bulk phase formation region, whereas $\mathrm{Mn}_{3} \mathrm{O}_{4}$ and $\mathrm{Mn}_{2} \mathrm{O}_{3}$ also extend well outside of that expected phase space, indicating that these phases in thin film form are metastable. The difference in processing environment, specifically the lack of hydration and alkali, and the presence of oxygen-containing plasma in the PLD chamber, likely also contribute to the differences between the thin film and bulk or nanoparticle growth. Because some materials can become more stable at decreased sizes as the surface energy becomes dominant, it is also worthwhile comparing the phases seen here with those seen during the early stages of growth. ${ }^{30}$ Just as the experimentally measured phase formation trends reported in Fig. 3 do not fit the bulk phase diagram, ${ }^{29}$ the phase regions seen in these libraries also do not fit the trends seen for anhydrous $10 \mathrm{~nm}$ nanoparticles of manganese oxides. ${ }^{30}$ This suggests that the metastable phases seen here in thin film form are not a captured remnant from a time when they were the stable phase during bulk synthesis or nanoparticle nucleation. ${ }^{6,9}$
It may be expected that the film growth should follow the bulk phase diagram trends for growth at a high temperature due to thermodynamic equilibration, and that the phase formation would favor the target composition at a low temperature due to kinetic limitations. While other oxide thin films have been shown to favor the target composition at lower temperature, ${ }^{24,37}$ these manganese oxide films neither favor the target compositions at low temperature, nor does the film formation follow the expected thermodynamic phase at high temperature. Rather, it was the oxidation environment during deposition that determined the phase formation, as influenced by the oxygen partial pressure and to a lesser extent the total pressure during the deposition. This could stem, in part, from reactive oxygen species that are present in the plasma during laser ablation in PLD. Furthermore, the phase regions were comparatively insensitive to temperature compared to the bulk- and nanoparticle phase diagrams. ${ }^{29,30}$ Note that the "effective" temperature in PLD may be very different from the plasma temperature or the substrate temperature, ${ }^{38}$ which could also play a role in the observed temperature differences with the bulk phase diagram. There are many potential benefits of decreasing the temperature needed for phase formation of manganese oxide thin films compared to the bulk, such as expanding the range of substrates that can be used for synthesis, as well as quenching in different defect concentrations.

\section{Conclusions}

$\mathrm{Mn}_{2} \mathrm{O}_{3}, \mathrm{Mn}_{3} \mathrm{O}_{4}$, and $\mathrm{MnO}$ phases are stabilized using PLD far from the equilibrium phase regions determined for bulk and nanoparticle manganese oxides. The oxygen partial pressure is the strongest factor determining the phase formation in PLD thin films, so much so that multiple phases could be targeted by varying the oxygen content alone while all other variables are held constant. The substrate temperature, total pressure in the 
chamber and target composition $\left(\mathrm{Mn}_{2} \mathrm{O}_{3}, \mathrm{MnO}_{2}\right.$, and $\left.\mathrm{MnO}\right)$ have a smaller and more complex effect on the phase formation, suggesting that there is yet more to understand about how the kinetics of deposition influence the phase formation. Visualization of the complex phase relationships is made possible using XRD and Raman/FTIR spectroscopy concurrently, to provide complementary views on the material structure and assess the full picture behind the phase formation in manganese oxide thin films grown using PLD. Studying the non-equilibrium PLD growth of manganese oxide thin films not only provides insights into the phase formation in this material system, but also points to routes for capturing phases of manganese oxides at lower temperatures or higher pressures than those necessary for solidstate or solution processing.

\section{Author contributions}

Films were made by A. Z. and L. G., XRD and Raman spectroscopy were performed by L. G., A. Z., and P. S., FTIR and RBS were performed by J. P., analysis was conducted by J. P., L. G., P. S., and A. Z., the project was led by D. G., and the paper was written by L. G. with contributions from all authors. All authors have given approval to the final version of the manuscript.

\section{Conflicts of interest}

There are no conflicts to declare.

\section{Acknowledgements}

This work was authored in part by the National Renewable Energy Laboratory (NREL), operated by Alliance for Sustainable Energy LLC, for the U.S. Department of Energy (DOE) under contract no. DE-AC36-08GO28308. Funding was provided by the Office of Science, Basic Energy Sciences (BES), as a part of Energy Frontier Research Center "Center for the Next Generation of Materials by Design”, and by the Office of Energy Efficiency and Renewable Energy (EERE) Hydrogen and Fuel Cell Technologies Office (HFTO), as a part of HydroGEN Energy Materials Network (EMN) consortium. The views expressed in the article do not necessarily represent the views of the DOE or the U.S. Government. L. G. would like to acknowledge the support of the Jerome and Isabella Karle Distinguished Scholar Fellowship from the U.S. Naval Research Laboratory.

\section{References}

1 K. Zhong, B. Zhang, S. Luo, W. Wen, H. Li, X. Huang and L. Chen, Investigation on porous $\mathrm{MnO}$ microsphere anode for lithium ion batteries, J. Power Sources, 2011, 196, 6802-6808.

2 Q. Xia, S. Sun, J. Xu, F. Zan, J. Yue, Q. Zhang, L. Gu and H. Xia, Self-Standing 3D Cathodes for All-Solid-State Thin Film Lithium Batteries with Improved Interface Kinetics, Small, 2018, 14, 1804149.
3 H. Pan, Y. Shao, P. Yan, Y. Cheng, K. S. Han, Z. Nie, C. Wang, J. Yang, X. Li, P. Bhattacharya, K. T. Mueller and J. Liu, Reversible aqueous zinc/manganese oxide energy storage from conversion reactions, Nat. Energy, 2016, 1, 1-7.

4 M. Huynh, C. Shi, S. J. L. Billinge and D. G. Nocera, Nature of Activated Manganese Oxide for Oxygen Evolution, J. Am. Chem. Soc., 2015, 137, 14887-14904.

5 B. Xu, Y. Bhawe and M. E. Davis, Low-temperature, manganese oxide-based, thermochemical water splitting cycle, Proc. Natl. Acad. Sci. U. S. A., 2012, 109, 9260-9264.

6 W. Sun, D. A. Kitchaev, D. Kramer and G. Ceder, Nonequilibrium crystallization pathways of manganese oxides in aqueous solution, Nat. Commun., 2019, 10, 573, DOI: 10.1038/s41467-019-08494-6.

7 J. E. Post, Manganese oxide minerals: Crystal structures and economic and environmental significance, Proc. Natl. Acad. Sci. U. S. A., 1999, 96, 3447-3454.

8 D. A. Kitchaev, S. T. Dacek, W. Sun and G. Ceder, Thermodynamics of Phase Selection in MnO2 Framework Structures through Alkali Intercalation and Hydration, J. Am. Chem. Soc., 2017, 139, 2672-2681.

9 B. R. Chen, W. Sun, D. A. Kitchaev, J. S. Mangum, V. Thampy, L. M. Garten, D. S. Ginley, B. P. Gorman, K. H. Stone, G. Ceder, M. F. Toney and L. T. Schelhas, Understanding crystallization pathways leading to manganese oxide polymorph formation, Nat. Commun., 2018, 9, 2553, DOI: 10.1038/s41467-018-04917-y.

10 H.-U. Krebs, M. Weisheit, J. Faupel, E. Süske, T. Scharf, C. Fuhse, M. Störmer, K. Sturm, M. Seibt, H. Kijewski, D. Nelke, E. Panchenko and M. Buback, Adv. Solid State Phys, 2003, 43, 505-518.

11 R. Eason, Pulsed Laser Deposition of Thin Films: ApplicationsLed Growth of Functional Materials, Wiley Online Library, Wiley-Blackwell, 2006.

12 S. Isber, E. Majdalani, M. Tabbal, T. Christidis, K. Zahraman and B. Nsouli, Study of manganese oxide thin films grown by pulsed laser deposition, Thin Solid Films, 2009, 517, 1592-1595.

13 H. Xia, Y. Wan, F. Yan and L. Lu, Manganese oxide thin films prepared by pulsed laser deposition for thin film microbatteries, Mater. Chem. Phys., 2014, 143, 720-727.

14 D. Nayak, S. Ghosh and V. Adyam, Thin film manganese oxide polymorphs as anode for sodium-ion batteries: An electrochemical and DFT based study, Mater. Chem. Phys., 2018, 217, 82-89.

15 D. Yang, Pulsed laser deposition of manganese oxide thin films for supercapacitor applications, J. Power Sources, 2011, 196, 8843-8849.

16 R. M. Valletta and W. A. Pliskin, Preparation and Characterization of Manganese Oxide Thin Films, J. Electrochem. Soc., 1967, 114, 944.

17 C.-C. Lin and P.-Y. Lin, Capacitive Manganese Oxide Thin Films Deposited by Reactive Direct Current Sputtering, J. Electrochem. Soc., 2010, 157, A753.

18 A. Ludwig, npj Comput. Mater., 2019, 5, 70.

19 M. L. Green, C. L. Choi, J. R. Hattrick-Simpers, A. M. Joshi, I. Takeuchi, S. C. Barron, E. Campo, T. Chiang, S. Empedocles, 
J. M. Gregoire, A. G. Kusne, J. Martin, A. Mehta, K. Persson, Z. Trautt, J. Van Duren and A. Zakutayev, Appl. Phys. Rev., 2017, 4, 011105.

20 H. Peng, P. F. Ndione, D. S. Ginley, A. Zakutayev and S. Lany, Design of Semiconducting Tetrahedral $\mathrm{Mn}_{1-x} \mathrm{Zn}_{x} \mathrm{O}$ Alloys and Their Application to Solar Water Splitting, Phys. Rev. X, 2015, 5(2), 021016, DOI: 10.1103/PhysRevX.5.021016.

21 D. A. Keller, A. Ginsburg, H. N. Barad, K. Shimanovich, Y. Bouhadana, E. Rosh-Hodesh, I. Takeuchi, H. Aviv, Y. R. Tischler, A. Y. Anderson and A. Zaban, Utilizing Pulsed Laser Deposition Lateral Inhomogeneity as a Tool in Combinatorial Material Science, ACS Comb. Sci., 2015, 17, 209-216.

22 N. D. Bassim, P. K. Schenck, E. U. Donev, E. J. Heilweil, E. Cockayne, M. L. Green and L. C. Feldman, Effects of temperature and oxygen pressure on binary oxide growth using aperture-controlled combinatorial pulsed-laser deposition, Appl. Surf. Sci., 2007, 254, 785-788.

23 A. Y. Anderson, Y. Bouhadana, H. N. Barad, B. Kupfer, E. RoshHodesh, H. Aviv, Y. R. Tischler, S. Rühle and A. Zaban, Quantum efficiency and bandgap analysis for combinatorial photovoltaics: Sorting activity of $\mathrm{Cu}-\mathrm{O}$ compounds in all-oxide device libraries, ACS Comb. Sci., 2014, 16, 53-65.

24 A. Subramaniyan, J. D. Perkins, R. P. O’Hayre, S. Lany, V. Stevanovic, D. S. Ginley and A. Zakutayev, Nonequilibrium deposition of phase pure $\mathrm{Cu}_{2} \mathrm{O}$ thin films at reduced growth temperature, APL Mater., 2014, 2, 022105, DOI: $10.1063 / 1.4865457$.

25 L. M. Garten, A. Zakutayev, J. D. Perkins, B. P. Gorman, P. F. Ndione and D. S. Ginley, Structure property relationships in gallium oxide thin films grown by pulsed laser deposition, MRS Commun., 2016, 6(4), 348, DOI: 10.1557/mrc.2016.50.

26 K. R. Talley, S. R. Bauers, C. L. Melamed, M. C. Papac, K. N. Heinselman, I. Khan, D. M. Roberts, V. Jacobson, A. Mis, G. L. Brennecka, J. D. Perkins and A. Zakutayev, COMBIgor: Data-analysis package for combinatorial materials science, ACS Comb. Sci., 2019, 21, 537-547.

27 A. Zakutayev, N. Wunder, M. Schwarting, J. D. Perkins, R. White, K. Munch, W. Tumas and C. Phillips, An open experimental database for exploring inorganic materials, Sci. Data, 2018, 5, 180053.
28 P. F. Ndione, E. L. Ratcliff, S. R. Dey, E. L. Warren, H. Peng, A. M. Holder, S. Lany, B. P. Gorman, M. M. Al-Jassim, T. G. Deutsch, A. Zakutayev and D. S. Ginley, High-Throughput Experimental Study of Wurtzite $\mathrm{Mn}_{1-x} \mathrm{Zn}_{x} \mathrm{O}$ Alloys for Water Splitting Applications, ACS Omega, 2019, 4, 7436-7447.

29 S. Fritsch and A. Navrotsky, Thermodynamic properties of manganese oxides, J. Am. Ceram. Soc., 1996, 79, 1761-1768.

30 N. R. Birkner, Thermodynamics of Manganese Oxides at Bulk and Nanoscale: Phase Formation, Transformation, OxidationReduction, and Hydration, University of California, Davis, 2015.

31 F. Buciuman, F. Patcas, R. Craciun and D. R. T. Zahn, Vibrational spectroscopy of bulk and supported manganese oxides, Phys. Chem. Chem. Phys., 1999, 1, 185-190.

32 M. J. Radler, J. B. Cohen, G. P. Sykora, T. Mason, D. E. Ellis and J. Faber, The defect structures of $\mathrm{Mn}_{1-x} \mathrm{O}$, J. Phys. Chem. Solids, 1992, 53, 141-154.

33 D. Jarosch, Crystal structure refinement and reflectance measurements of hausmannite, $\mathrm{Mn}_{3} \mathrm{O}_{4}$, Mineral. Petrol., 1987, 37, 15-23.

34 S. Geller, Structure of $\alpha-\mathrm{Mn}_{2} \mathrm{O}_{3},\left(\mathrm{Mn}_{0.983} \mathrm{Fe}_{0.017}\right)_{2} \mathrm{O}_{3}$ and $\left(\mathrm{Mn}_{0.37} \mathrm{Fe}_{0.63}\right)_{2} \mathrm{O}_{3}$ and relation to magnetic ordering, Acta Crystallogr., Sect. B: Struct. Crystallogr. Cryst. Chem., 1971, 27, 821-828.

35 R. Naeem, M. Ali Ehsan, R. Yahya, M. Sohail, H. Khaledi and M. Mazhar, Fabrication of pristine $\mathrm{Mn}_{2} \mathrm{O}_{3}$ and $\mathrm{Ag}-\mathrm{Mn}_{2} \mathrm{O}_{3}$ composite thin films by AACVD for photoelectrochemical water splitting, Dalton Trans., 2016, 45, 14928-14939.

36 S. H. Shim, D. LaBounty and T. S. Duffy, Raman spectra of bixbyite, $\mathrm{Mn}_{2} \mathrm{O}_{3}$, up to $40 \mathrm{GPa}$, Phys. Chem. Miner., 2011, 38, 685-691.

37 A. Subramaniyan, J. D. Perkins, R. P. O’Hayre, D. S. Ginley, S. Lany and A. Zakutayev, Non-equilibrium synthesis, structure, and opto-electronic properties of $\mathrm{Cu}_{2-2 x} \mathrm{Zn}_{x} \mathrm{O}$ alloys, J. Mater. Sci., 2015, 50, 1350-1357.

38 P. F. Ndione, Y. Shi, V. Stevanovic, S. Lany, A. Zakutayev, P. A. Parilla, J. D. Perkins, J. J. Berry, D. S. Ginley and M. F. Toney, Control of the Electrical Properties in Spinel Oxides by Manipulating the Cation Disorder, Adv. Funct. Mater., 2014, 24, 610-618. 